\title{
OPERATIONAL CONTROL IN THE PROCESS SAFETY ASSURANCE
}

doi: $\quad 10.2478 /$ czoto-2019-0016

Date of submission of the article to the Editor: 05/12/2018

Date of acceptance of the article by the Editor: 23/01/2019

Tatiana Karkoszka - orcid id: 0000-0002-7853-3654

Silesian University of Technology Poland, tatiana.karkoszka@polsı.pl

\begin{abstract}
The need of ensure the safety in the realised industrial processes results directly from their negative influence both on environment and workers' health, and, as a result - the associated material losses. Safety management must be based on the risk management, results of which are the basis of risk acceptability assessment and taking action of the systemic character directed on risk minimisation. Those actions should guarantee technical condition of the used technological installations and monitoring and control equipment as well as organisational solutions, which in the effective manner are going to minimise the probability of occurrence of environmental and occupational accidents, and - in the case of their occurrence - minimise the influences. Therefore research on the practical solutions of process safety assurance, both in the regular conditions of work and in the time of the emergency are of the crucial meaning. That is why the value of the paper is being constituted by the authorial model of operational control, which aim is to guarantee the process safety from the perspective of the both: technical and occupational safety. The worked out model is the systemic tool giving the guidelines of operational management and allowing for the homogeneous management in the range of environmental safety and occupational safety and on the basis of - being the fundamental element of the model - risk management. The worked out model can be implemented in case of any organisation which wants to assure the safety of the realised processes by risk and system management.
\end{abstract}

Keywords: environmental and occupational safety, risk, safety management, operational control

\section{INTRODUCTION}

The increasing quality and quantity requirements entail a dynamic development of industry. Most commonly it is accompanied by the increase in the environmental influence and particularly difficult working conditions. Such a situation concerns especially a process industry, where large quantities of chemical substances and/or energy are used, and while being released to the environment can lead to very serious human, environmental and material loss. It shows the urgency of process safety assurance, not only in the process industry but in every organisation, where the 
need for integrated environmental and occupational risk management is recognised (Liao et al., 2017).

Process safety is described as an organisation strategy directed on safe critical decision making deriving from the effects of: identification and analysis of threats, assessment and evaluation of risk and measures of safety (Gibson, 1999). Process safety can't be understood directly as occupational safety, because its main aim is to prevent accidents (Bahr, 1997). However it must not be forgotten that accidents should be treated as occupational threats including thereby occupational safety in the range of process safety. The measure of the process safety is risk, which should be interpreted as the combination of the probability of an event and its consequences (Häring, 2015; Ericson, 2016). Therefore safety management based on the risk management includes threats and risks identification, risks analysing, risks evaluation and risk-based decision making oriented towards changing initial situation (Häring, 2015; Khan et al., 2015).

Process safety management should include the systemic actions concerning both technical/technological and organisational solutions. Modern productive maintenance, being the element of total productive maintenance strategy and having the preventive character, makes it possible to assure the essential equipment and its proper operation. However, fulfilment of the system requirements connected with the operational control - concerning identification of crucial threats, preparedness for environmental and occupational accidents, monitoring as well as competences, trainings, motivation and information and communication - should assure the safety in the organisational context.

The systemic requirements have been characterised in the amended ISO 14001 standard which includes the guidelines for functioning of the environmental management system and in new international standard ISO 45001 which describes the guidelines for occupational health and safety management system (ISO 14001, 2015; ISO 45001, 2017). When implemented in the integrated and complementary manner, they can be treated as a formal guidelines for safety management system being a framework for procedures and processes used by an organisation to achieve safety purposes and objectives. In the context of process safety assurance the operational level points - Planning, Support and Operation - are the most meaningful ones (Table 1).

Processes should be planned with consideration of occupational and environmental both risks and opportunities. Every planned action should be adequate to their influence on conformity assurance (Planning). In the planning one should take into consideration the necessity of assurance and maintenance of equipment having crucial influence on the process safety. The significance of roles, responsibilities, accountabilities, authorities, trainings and awareness as well as information and communication, and documented information for process' safety has been underlined (Support). Organisation realises the planned aims by the assurance of the supervised conditions and prevention against the deviation from the planned occupational and environmental objectives. When deviations occur organisation is prepared to remove or minimise their influences (Operation). 
Table 1

Comparison of the new requirements of ISO 45001 and ISO 14001 norms

from the scope of Planning, Support and Operation (ISO 45001, 2017; ISO 14001, 2015)

\begin{tabular}{|c|c|}
\hline ISO $\mathbf{4 5 0 0 1}$ & ISO 14001 \\
\hline \multicolumn{2}{|c|}{ Planning (6) } \\
\hline \multicolumn{2}{|c|}{ Actions to address risks and opportunities (6.1) } \\
\hline $\begin{array}{c}\text { Occupational safety objectives } \\
\text { and planning to achieve them (6.2) }\end{array}$ & $\begin{array}{c}\text { Environmental objectives and planning } \\
\text { to achieve them (6.2) }\end{array}$ \\
\hline \multicolumn{2}{|c|}{ Support (7) } \\
\hline \multicolumn{2}{|c|}{$\begin{array}{c}\text { Resources (7.1), Competence (7.2), Awareness (7.3), } \\
\text { Communication (7.4), Documented information (7.5) }\end{array}$} \\
\hline \multicolumn{2}{|c|}{ Operation (8) } \\
\hline \multicolumn{2}{|c|}{ Operational planning and control (8.1) } \\
\hline \multicolumn{2}{|c|}{ Emergency preparedness and response (8.2) } \\
\hline
\end{tabular}

It should be underlined that the fundament of the process safety management - being also a consequence of systemic requirements - is identification of the threats of the crucial character, which can have a decisive impact on emergency occurrence and, subsequently, on the decision making directed on their elimination. So, the key element of planning in the safety management is risk management including: threats identification, assessment of the losses connected with occurrence of threats' effects and probability of occurrence, risk acceptability evaluation. Risk management is directed on maintenance of the risk on the as low as possible and reasonably justified level (ALARP). The value of the socially accepted risk, both in the range of the work safety and environmental aspect, has not been defined either in the legal regulations or the normative requirements or customary norms. The organisation decides by itself, which techniques of the risk's assessment will turn out to be effective and which risk will be approved as the acceptable ones (Aven, 2010; Aven, 2014).

While considering the above study, one has undertaken the trial of systematise the organisational actions, covering the occupational and environmental safety, based on the risk management and aiming at ensuring the process safety to the organisation.

\section{METHODOLOGY}

The main aim of the research was preparation of the universal model of process safety assurance.

The actions realised in the range of the model take into account simultaneously deciding about process safety assurance - environmental and occupational safety aspects.

The model is of the descriptive character. It is an explanation of the complex guidelines, which can be applied in every - not only maintaining the process installations - organisation realising technological processes and directed on the process safety assurance.

Its utilisation allows for fulfilment of the formalised requirements of environmental and occupational management systems includes in ISO 14001:2015 and ISO 45001:2017 standards (see Table 1). 


\section{RESULTS AND DISSCUSSION}

The proposed model includes the steps taken in the conditions of "supervised risk" ensured by monitoring of the identified operational criteria together with emergency actions and reactive monitoring directed on the risk minimisation and process safety assurance - Figure 1.

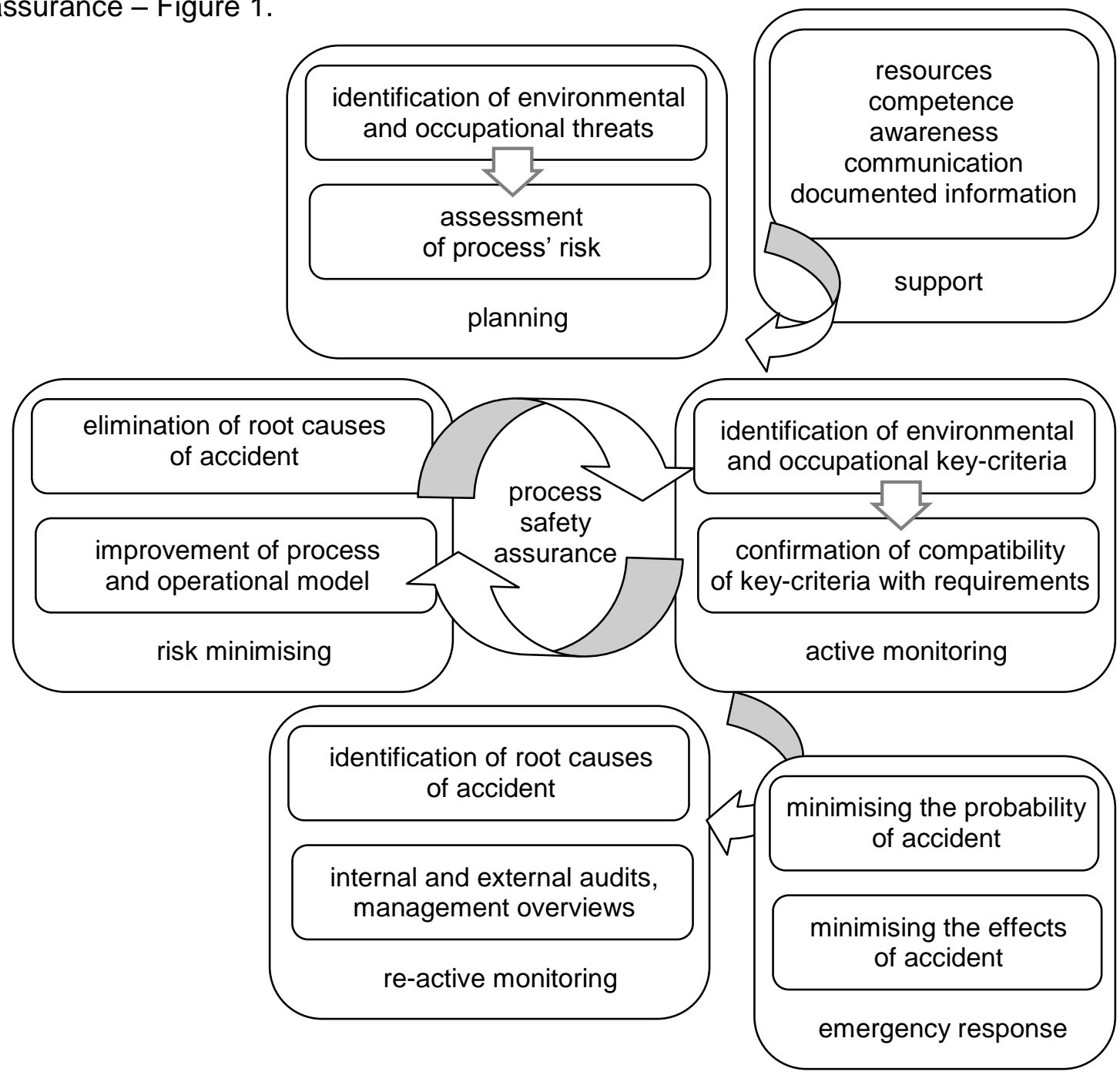

Fig. 1. Model of the process safety assurance in the context of environmental and occupational risk

During the time of the operational planning, the organisation plans the safety of the processes in consideration of the environmental and occupational objectives and methods to achieve them. It defines the necessary human resources and the intangible ones, ways of supervising the processes - also the control processes, methods of threats identification and risk assessment, and documentation. The risk assessment based on the environmental and occupational health and safety criterion, which may be applied during the operational control, constitute the subject of the author's study and have been described in the following scientific papers (Karkoszka, 2017a; Karkoszka, 2017b). Based on the results of the assessment, the organisation plans and implements organisational, technical and technological solutions, which are suitable for the risk connected with environmental and occupational health and safety threats, and which aim is to prevent the risk and its prospective minimising. 
The integrated risk estimation is a basis for pointing the threats for the process having a meaningful character for fulfilment of the requirements of all the interested parties. The operations connected with the meaningful threats undergo special supervision by operational monitoring, which aim is to prevent occurring the effects of these threats as well as reacting to the emergencies, when the effects of the threats occur.

Operational monitoring is of the typical preventive character. It is a way of the operational risk management by the realisation of the processes in the supervised conditions while guarantying the compatibilities of the key-criteria and the operational features with the legal requirements, technical specifications and other requirements. The proposed method of the operational monitoring - identification of the keycharacter operational features and criteria have been described in the following papers (Karkoszka, 2017a; Karkoszka, 2018).

At the same time the organisation is prepared to the indispensable actions in the situations when the effects of the meaningful threats became real ones. This is a sort of action in case of the emergency and it reflects in the reality the processes aiming at maintaining the continuality of the action. Actions in case of the emergency cover the organisational and technological solutions concerning the following: preventing, preparedness and response to the potential effects of the threats based on the environmental and occupational health and safety criteria. The procedure prepared with participation of all of the interested parties, guarantees the supervision of the results of threats, and especially by ensuring the following: necessary information, internal communication and coordination aiming at protection of all the interested parties, as well as actions minimising the effects of the key-threats by removing the occurred effects of the threat or their allowance.

The results of the integrated threats constituting the incompatibilities with the operational criteria, which embodied in the organisation despite the operational control and the actions undertaken for the sake of the emergency, undergo the analysis during the reactive monitoring time. Its aim is to minimising the risk connected with the threats resulting on the appearance of the influences on the environment as well as the occupational diseases and the accidents at the workplace.

Organisation both: in case of stating the unconformities in the processes, taking up the emergency actions and reactive monitoring as well as the identification of the necessity of improvement, undertakes the actions of development. These actions undergo planning and determination of the risk.

\section{CONCLUSIONS}

It's up to organisation to decide what kind of technical and organisational security systems of the realised processes are going to be used to prevent the accident and what kind of measures are going to be taken when the effects of the accident become a reality. The decision taken on the process safety, however, should have the explanation being the effect of the assessment of the risk significance and acceptability. Such activities can be effective only when the safety management is of the systemic character, and the risk management constitutes its elementary part, also of the systemic nature. 
The developed model, being the guidelines for the process safety assurance, adheres to those principles. It should be treated as an interdisciplinary tool for shaping both technical and organisational aspects of the realised processes.

The model - by the assessment of the process risk, operational monitoring in the supervised conditions, actions in case of the emergency and reactive monitoring can form the practical basis for assurance of the processes compatibility, prevention of the accidents, minimisation of their effects if they occur and improvement of process safety. In the organisation, which wants to assure the process safety in the systemic manner - using the risk management - the proposed model will allow the coherent management of threats and their effects in the environmental and occupational range and facilitate the achievement of process safety. Thereby its implementation will simplify the fulfilment of the requirements of ISO 45001 and ISO 14001 standards and regarding to the process planning and realisation.

\section{REFERENCES}

Aven, T., 2010. On how to define, understand and describe risk. Reliability Engineering and System Safety, 95(6), 623-631, DOI: 10.1016/j.ress.2010.01.011.

Aven, T., 2014. What is safety science? Safety science, 67, 15-20, DOI: 10.1016/j.ssci.2013.07.026

Bahr, N.J., 2015. System safety engineering and risk assessment. A practical approach. CRC Press, Boca Raton, USA.

Ericson, C.A., 2016. Hazard analysis techniques for system safety. John Wiley \& Sons, Inc., Hoboken, USA.

Gibson, N., 1999. Process safety - a subject for scientific research. Transactions of the Institution of Chemical Engineers, 77, 153-179.

Häring, I., 2015. Risk analysis and management: engineering resilience. Springer Science, Singapore, Heidelberg, New York, Dordrecht, London, DOI: 10.1007/978981-10-0015-7_2

Karkoszka, T., 2017a. Operational control with application of the risk analysis in the integrated management system of technological process. Silesian Technical University, Gliwice, Poland.

Karkoszka, T., 2017b. Operational monitoring in the technological process in the aspect of occupational risk. Procedia manufacturing, 13, 1463-1469, DOI: 10.1016/j.promfg.2017.09.192

Karkoszka T., 2018. Determination of the key operational features in the steel continuous casting processes, Metalurgija, 57, 135-138.

Khan, F., Rathnayaka, S., Ahmed, S., 2015. Methods and models in process safety and risk management: past, present and future. Process safety and environmental protection, 98, 116-147, DOI: 10.1016/j.psep.2015.07.005

Liao, Y., Deschamps, F., Loures, E.F.R., Ramos, L.F.P., 2017. Past, present and future of Industry 4.0 - a systematic literature review and research agenda proposal. International Journal of Production Research, 55(12), 3609-3629, DOI: 10.1080/00207543.2017.1308576.

ISO 14001, 2015. Environmental management systems - Requirements with guidance for use. ISO, Genève, Switzerland.

ISO 45001, 2017. Occupational health and safety management systems Requirements with guidance for use. ISO, Genève, Switzerland. 